\title{
AURICULAR FIBRILLATION AND AURICULAR FLUTTER IN DIPHTHERIA
}

\author{
BY \\ C. NEUBAUER \\ From the City Hospital for Infectious Diseases, Newcastle upon Tyne \\ Received October 10, 1944
}

Auricular fibrillation and auricular flutter are generally regarded as uncommon heart disorders in children-a fact that is illustrated by their omission from many textbooks of pædiatrics. Auricular fibrillation develops in mitral stenosis due to rheumatic involvement of the heart, when it appears generally after the age of puberty; but it can occur in children of all ages in the course of a severe acute infectious disease, especially diphtheria. The reports of auricular fibrillation and auricular flutter occurring in diphtheria are not numerous: Burkhardt (1938) could not detect one case of auricular fibrillation amongst 140 cases of diphtheria examined electrocardiographically every second or third day; Bourne (1941) described one case of diphtheritic myocarditis with auricular flutter in a woman aged 79 years; Campbell et al. (1943) reported a case of transient auricular fibrillation in a youth of 22 years. Another report, Neubauer (1942), recorded three cases of auricular fibrillation in a series of 100 cases of diphtheritic heart disorders in children.

Altogether 6 cases of auricular fibrillation among a series of 200 cases of diphtheritic myocarditis have now been observed between June, 1941, and June, 1944, that is an incidence of 3 per cent. It occurred in 5 children and 1 adult: their ages were 2 years and 5 months, 2 years and 9 months, 6, 8, 10, and 28 years. The auricular fibrillation was associated with severe myocarditis and in all cases an involvement of the conducting system was found by cardiographic records. Partial auriculo-ventricular block was found in four patients and complete block in the other two, whose ages were 2 years and 5 months, and 6 years. The heart action was found slow (40-75 a minute) and irregular in partial A-V block and slow and regular in complete heart block. Examples are given in Fig. 1 and 2. The chief clinical signs observed were as follows:

\begin{tabular}{|c|c|c|c|c|c|c|c|c|c|}
\hline \multicolumn{9}{|c|}{ Cases } & Cases \\
\hline Syncope & .. & .. & .. & & .. 2 & Engorged jugular veins & . & .. & .. 2 \\
\hline Vomiting & .. & .. & .. & .. & .. 4 & Enlarged liver & $\ddot{.}$ & $\begin{array}{l}\cdots \\
.\end{array}$ & $\ddot{.}$ \\
\hline Cyanosis & & $\ldots$ & .. & $\ldots$ & .. 3 & Severe albuminuria.. & .. & .. & .. \\
\hline Enlarged & liac & llness & .. & .. & .. 4 & & & & \\
\hline
\end{tabular}

I

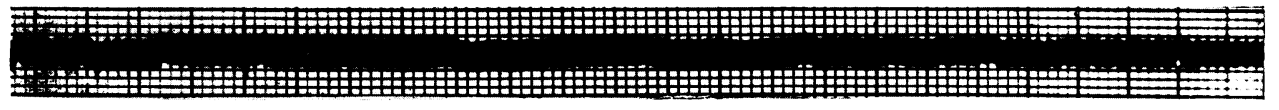

II

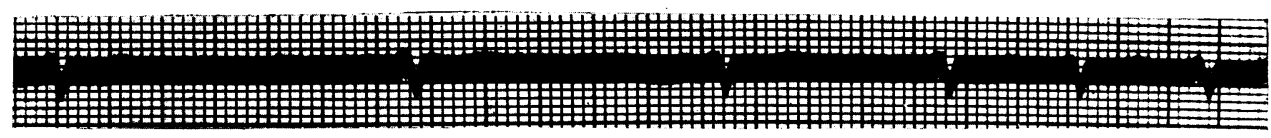

III

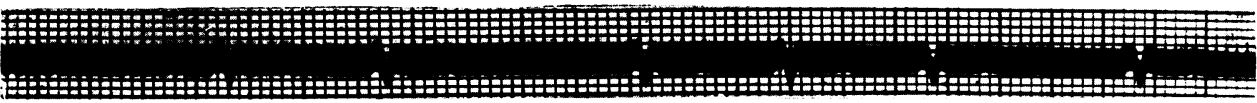

FIg. 1.--An example of auricular fibrillation with slow ventricular rate. The ventricular rate is about 50 a minute. QRS is of low voltage; S-T-T is almost isoelectric. The slow ventricular rate indicates some degree of partial A-V block. (D. E., 2 years and 9 months old, twelfth day of diphtheria.) 


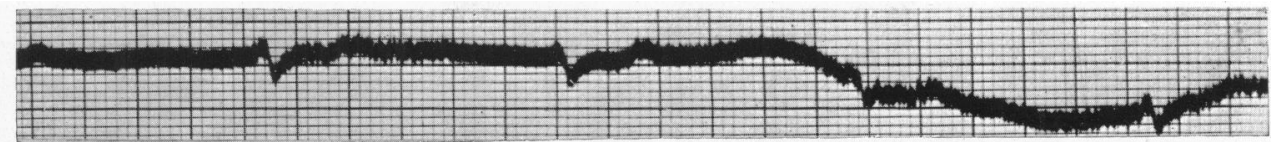

II

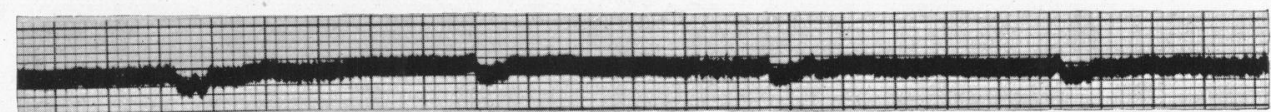

III

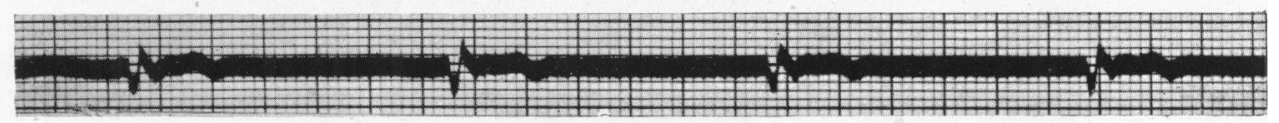

FIG. 2.-An example of auricular fibrillation with complete A-V block. The ventricular rate is about 49 a minute, regular. QRS is splintered and notched, of Q-type in lead III, and of low voltage, with a duration of 0.14 sec. T is small in leads I and II and inverted in lead III. (J. W., 2 years and 5 months old, eleventh day of diphtheria.)

The blood pressure was diminished in all instances, and the lowest readings were $56 / 30$ in the child 10 years of age. Four patients died, two recovered. The adult made a complete recovery from a partial A-V block: she developed palatal, pharyngeal, facial, and hypoglossal paralysis and peripheral neuritis of the legs in the course of the disease and she was discharged after three and a half months. The other patient who recovered was the girl of six with complete heart block, palatal and pharyngeal paralysis, and peripheral neuritis of the legs; she was discharged with no clinical signs present in her heart and with an almost normal cardiogram after three months. The death occurred in one patient 2 years and 5 months old (Fig. 2) on the eleventh day of disease; two children, 2 years and 9 months and 8 years of age, died on the sixteenth day of disease, and another patient of 10 years died on the fortyfourth day of the disease.

To supplement the limited number of reports on auricular fibrillation and auricular flutter in childhood, the following account of a case is given, with clinical, cardiographic, and pathological findings.

History. L. A., aged 5 years. Previous diseases; chicken pox in 1941 and measles in 1943. The child had not been inoculated against diphtheria. On May 12, 1944, she began to vomit, developed a sore throat and a slight croupy cough, and was admitted to hospital two days later.

On admission the picture was not one of a very ill child. Examination revealed the presence of œedema in the throat and membrane covering both tonsils; enlarged cervical glands and oral fœetor were noted. A bacteriological examination of the throat swabs showed the presence of C. Diphtheria and S. Hamolyticus. The child was given 20,000 units of diphtheria antitoxin. A regular tachycardia was present at this stage, the heart sounds being normal.

The course of the disease was as follows:

May 18 (7th day of the disease). A punctate rash appeared on the trunk, the throat was highly inflamed, and the tongue was peeling at the tip and on the edges.

May 20. Severe albuminuria, a sign of bad prognosis, manifested itself. Tachycardia persisted.

May 21. Red strawberry tongue. The first apical heart sound was found to be diminished in intensity; the pulse rate was 124 and the blood pressure $65 / 35$. The child was restless and the general condition had deteriorated, the colour being poor. Blood sedimentation rate 21 in the first hour.

May 24. The child presented some cyanosis of the lips and distended jugular veins. The pulse was weak and irregular, the rate varying between 136-150. The heart action was irregular, the rate being 160-180 (Fig. 3).

May 25. Her condition was progressively worse. The pulse was soft, with a rate of about 160 (Fig. 4). The abdomen was slightly distended and the liver dullness increased.

May 26. The heart action appeared to be regular and the rate slower. The blood pressure was $85 / 50$, but the child was very restless and seemed to be having pain in the precordial region. The cardiographic findings were similar to those demonstrated in Fig. 4 showing auricular flutter with $2: 1$ block.

May 27 (16th day of disease). The child died.

Post-mortem findings (Professor Bernard Shaw). Heart weighs 104 grams. The pericardial sac contains a normal amount of free fluid. There is no pericarditis. The right auricle is slightly dilated and contains post-mortem thrombus. The foramen ovale is closed. The tricuspid valve admits two fingers and the cusps are thin and delicate. The right ventricle is not dilated, the muscle 


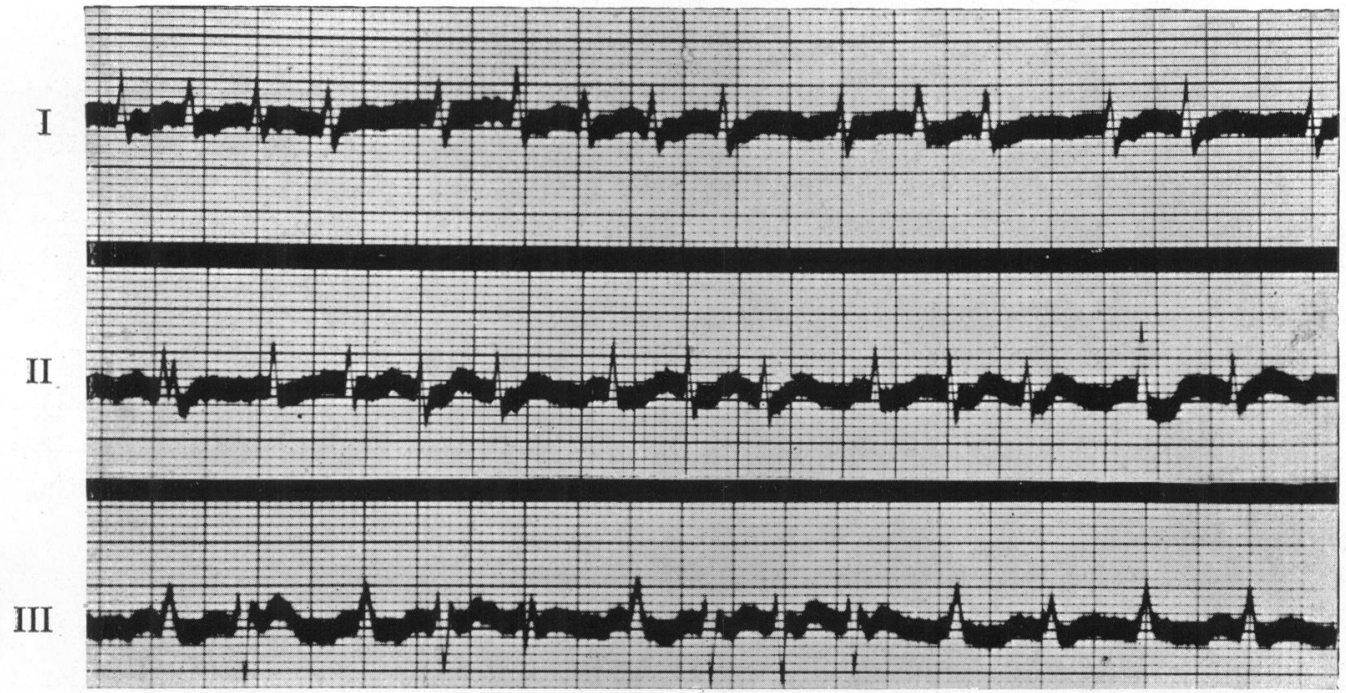

FIg. 3.-Auricular fibrillation. Heart action irregular. Rate about 180 a minute. No $P$ waves are visible. Fine undulations between the ventricular deflections, irregular in timing, voltage, and contour. (See text.)

I

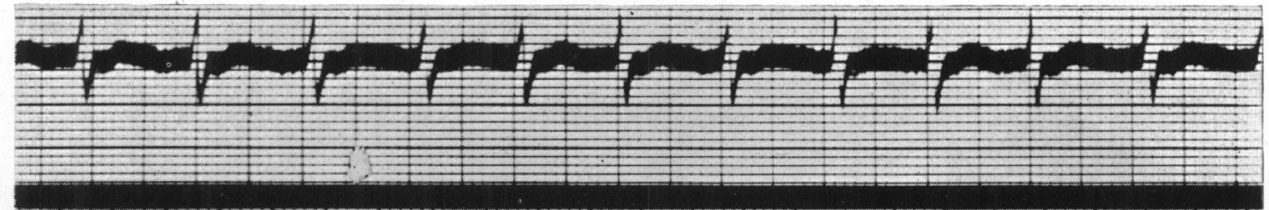

II

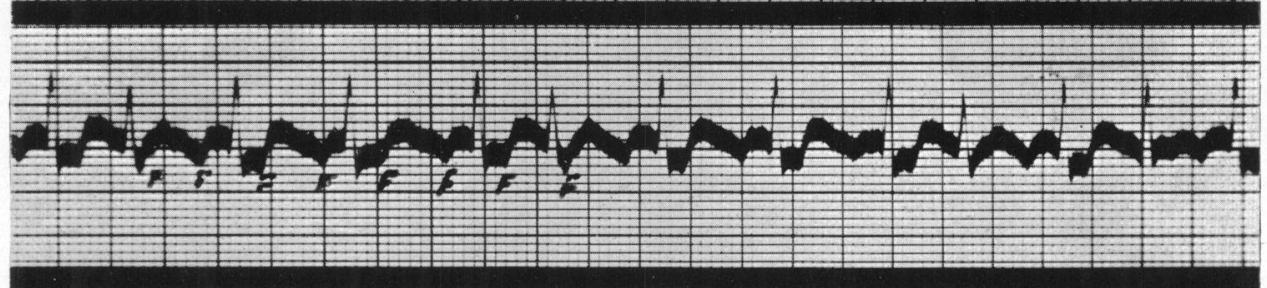

III

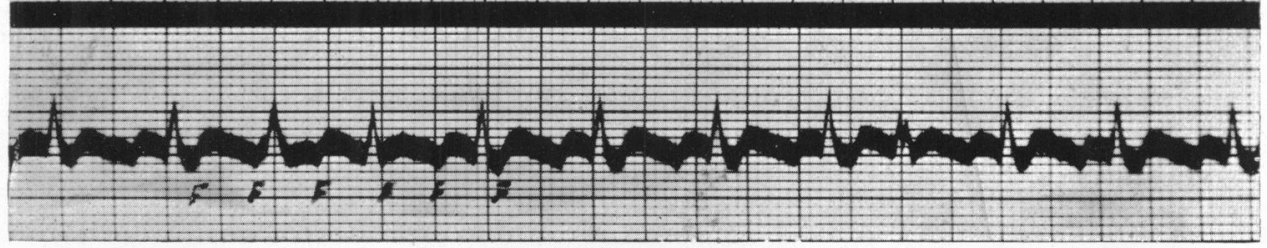

FIG. 4.-Auricular flutter with irregular block, $2: 1$ and $1: 1$. There are continuous regular flutter waves (F), best seen in lead II and III, occurring at the rate of 260 a minute. The ventricular rate is generally just half as rapid, 130 a minute.

being $0.4 \mathrm{~cm}$. in thickness at the base. The pulmonary artery is smooth and elastic. The left auricle contains post-mortem clot and the wall is slightly thicker than usual. The mitral valve admits one finger and the cusps and chordæ tendineæ are thin and delicate. The left ventricle is dilated and the muscle measures $0.9 \mathrm{~cm}$. in thickness at the base. The aortic valve is normal. The aorta shows some hæmoglobin stain. The coronary arteries are patent and free from atheroma. The myocardium is pale; there are no hæmorrhages and no evident fatty changes.

Histology. Sections of right auricle, tricuspid valve, right ventricle, left auricle, mitral valve, and left ventricle: these sections show an acute myocarditis involving the musculature of both auricles and both ventricles, but more marked in the left auricle and left ventricle; with regard to the latter the lesions occur with equal frequency at all levels.

The lesions consist of multiple small cellular foci consisting of mobile histiocytes, a few polymorphs, and eosinophils, situated in the stroma, but with no evident relation to the vessels. The muscle fibres show no necrosis and no fatty change. Hidden in the bays between the columnæ carneæ of the right auricle are multiple mural ante-mortem thrombi probably induced by fibrillation.

The lesions might be due either to diphtheria or scarlatina as there is no histological differentiation between the two. 


\section{DisCUSSION}

On clinical and bacteriological grounds, the case was one of faucial diphtheria. Hæmolytic streptococci are not uncommonly found in diphtheritic throat lesions caused by gravis strain, and in the case under discussion the presence of hæmolytic streptococci, in addition to the development of a rash and strawberry tongue as described above, indicates beyond doubt a double infection. The persistent tachycardia and the diminished intensity of the first apical sound, the lowered blood pressure, and increased blood sedimentation rate were clinical manifestations of a myocarditis. Auricular fibrillation, detected clinically and cardiographically three days later, confirmed the presence of myocarditis; it persisted for two days in spite of digitalis therapy and ultimately changed to auricular flutter. Anatomical and histological findings at autopsy revealed an acute myocarditis with formation of ante-mortem mural thrombi.

Here, then, is an example of auricular fibrillation and auricular flutter developing as terminal events in the course of an extremely acute myocarditis.

It is with the kind permission of Professor Bernard Shaw that the detailed post-mortem notes are included with the present report.

My thanks are also due to Dr. I. E. McCracken, M.O.H., Newcastle upon Tyne, and to Dr. G. Hurrell, Medical Superintendent, City Hospital for Infectious Diseases, Newcastle upon Tyne, for facilities provided.

Bourne, G. (1940). Lancet, 2, 96.

\section{REFERENCES}

Burkhardt, E. A., Eggleton, C., Smith, L. W. (1938). Amer. J. med. Sci., 195, 301.

Campbell, A. M. G., Gibson, P. C., Lane, C. R. T. (1943). Brit. Heart J., 5, 183.

Neubauer, C. (1942). Brit. med. J., 2, 91. 